\title{
The morphological traits variation and inter relationships of understorey species of Sal (Shorea robusta) forest of north-eastern Uttar Pradesh, India.
}

Satish Kumar Rai ${ }^{1}$, Ravindra P. Shukla ${ }^{1}$ and Sanjay Kumar Pandey*2

${ }^{1}$ Forest Ecology Laboratory, Department of Botany, DDU Gorakhpur University, Gorakhpur, Uttar Pradesh, India. 2Department of Botany, DAV PG College, Gorakhpur, Uttar Pradesh, India.

Received: 02/12/2018; Revised: 03/15/2018; Accepted: 03/25/2018

\begin{abstract}
Measurements of plant traits are required for evaluating community structure and its ecological responses to varying environmental conditions. The grouping on the basis of functional traits of plants has strong predictive power of important ecosystem responses to environmental perturbation. The morphological traits and their interrelationship among associated species have been analyzed to understand the quantitative variation within regional sal dominated forests. Data for five morphometric traits vi\%., plant height, leaf length, leaf width, flower size and fruit size, were observed for 193 woody (tree, shrub and liana) species belonging to 56 families within understorey of sal forest. Forty-one families were polytypic in nature. One-way ANOVA was used to detect how variation among all the traits was distributed among habit groups. A significant positive relationship was noticed between plant height and each of the leaf length, leaf width and fruit size. Of the different morphometric traits observed only plant height and fruit size showed wider variation among three life-form categories. Overall, our results suggest that measurement of plant morphometric characters are the major drivers of understory sal associates of the region. Hence, the morphological traits of sal associates should be carefully considered in framing the management and conservation strategy of regional sal forests.
\end{abstract}

Key words: Sal associates, Morphometric characters, Plant traits, Life form, Habit groups

\section{Introduction}

The functional composition of ecosystem has been found to be consistently associated with certain plant functional types and functional richness rather than the species richness (Diaz and cabido 2001). Various plant functions have strong impacts on ecosystem processes (Cornelissen et al., 1996) and these processes have a strong relationship with various plant traits with respect to their vegetative growth, reproductive strategy and nutrient use efficiency. Traits that determine how a species respond to a disturbance or change in environment (functional response traits) may differ from those that determine how that species affect ecosystem properties (functional effect traits, Lavorel et al., 1997, Walker et al., 1999). A functional group constitutes a set of species that have similar effect on a specific ecosystem process or similar responses to environmental conditions. When many traits are considered simultaneously a plant community can be characterized by the distribution and abundance of its phenotypic traits yielding a functional perspective on the plant community (Doledec and Chessel 1994).

The most favoured plant functional traits are those that are also relatively easy and inexpensive to measure for large numbers of plant species. They are called soft traits (Hodgson et al., 1999) and can

*Corresponding Author:

Dr. Sanjay Kumar Pandey

Department of Botany,

DAV PG College, Gorakhpur,

Uttar Pradesh, India.

E-mail: drskp27@gmail.com be measured with fare degree of precision (Hendry and Grime 1993, Westoby 1998, Cornelissen et al., 2003). The Inter-specific correlations among traits are the result of the adaptive outcome of natural selection. A particular combinations of traits may be depends over others combination (Lord et al., 1995, Westoby et al., 2002, Wright et al., 2005). A morphological trait like plant height associated with the plant competitive vigour, fecundity and regeneration time after a disturbance (Conelissen et al., 2003).

Leaf size also linked with plant size, twig size, and architecture. Species with larger leaves tend also to have less frequent branching and to bear larger fruits than species with smaller leaves (Corner's Rules, Corner 1949, Cornelissen 1999, Westoby and Wright 2003). Fonseca et al., (2000) observed 1000fold variation in leaf size among sets of cooccurring species and suggested that there must be additional costs and benefits associated with variation in leaf size. Other theoretical relation of leaf size with environmental factors and evolutionary approach has been developed by Givnish (1978, 1987), Cornelissen (1999), GregoryWodzicki (2000). Morphological traits of reproductive parts of the plants also play an important role in dynamics of plants populations 
because variation in floral morphology is of crucial importance to broadening our understanding of the mechanisms underlying angiospermic evolution. Wright et al., (2007) found an expected relationship among fruit size with plant height and leaf size. A number of studies on plant functional approach are available in India with reference to interrelationship among seed dynamics (Murali 1997), phenotypic traits (Sagar and Singh 2003) and functional trait analysis of liana community in tropical dry evergreen forest (Vivek and Parthasarathy 2015).

However, the functional aspect of morphological traits has been rarely attempted. The plant species content of north-eastern Uttar Pradesh is quite well known through taxonomic and phytosociological studies since 1960s (Srivastava 1976, Pandey and Shukla 2003, Shukla 2009, Srivastava et al., 2015). The grouping on the basis of functional characteristics of plants has strong predictive power of important ecosystem responses to environmental change. We measured five morphological trait attributes of understorey woody plants of sal forest. These are maximum plant height, leaf length, leaf width, flower size and fruit size. These traits are also ecologically important traits which reflect their significance in the variation and evolution of focal traits.

\section{Materials and Methods}

The forested landscape of north-eastern Uttar Pradesh includes 366 species under 83 families. Data for five morphometric traits vir., plant height, leaf length, leaf width, flower size and fruit size, were observed for 193 woody (tree, shrub and liana) species belonging to 56 families within understorey of sal forest. Plant heights (m) were measured with the help of clinometer as the maximum height for each species during field survey. At least 10 separate individuals of a species were used for measurement of height. For leaf trait measurement 20 leaves were taken from 10 non-damaged and mature individuals of a species. We measured leaf length $(\mathrm{cm})$ and leaf width $(\mathrm{cm})$ with simple measuring scale. Leaf length was the maximum length of frond excluding petiole. Leaf width was measured as the maximum diameter of the imaginary circle that can be fitted anywhere in the leaf (Westoby 1998, Cornelissen et al., 2003). For flower size $(\mathrm{cm})$ we measured fully opened, intact flowers with simple scale as the measure of the length of the corolla or perianth followed by Osunkoya (1996). Flower size was grouped into three categories: small $(<2 \mathrm{~cm})$, medium $(2-5 \mathrm{~cm})$ and large $(>5 \mathrm{~cm})$. For this trait we measured 3 flowers from each inflorescence of 10 different individuals of each species. Fruit size expanse was measured by multiplying its maximum length and width, accommodating the bias caused by long and linear fruits (Carpenter et al., 2003). The data were analyzed using each species as an independent observation. The G-test for goodness of fit was used to test for association between the distribution of flower size categories under habit groups and also with polytypic families. One-way ANOVA was used to detect how variation among all the traits was distributed among habit groups. Bivariate trait correlations, across all species were based on a data set of $\log _{10}$-transformed values. Relationship strength was quantified using regression coefficient $\left(\mathrm{R}^{2}\right)$ and $P$ values; relationship slope were described by their model II regression that means standardized major axes (SMA/MA). The data were computed by PAST 3.14 (Hammer 1999- 2012). A critical probability level of $p=0.05$ was used in hypotheses testing.

\section{Results}

Morphometric plant traits viz: plant height, leaf length and width, flower size and fruit size of 193 understorey plant species belonging to 56 families of sal forest was analyzed. Forty-one families were polytypic in nature. Tree species were quite greater in number followed by lianas and shrubs. These understorey species harbor quite large proportion $(63 \%)$ of small sized flowers followed by medium sized ones. Fewer than $9 \%$ of understorey plants had large size flower (Fig. 1).

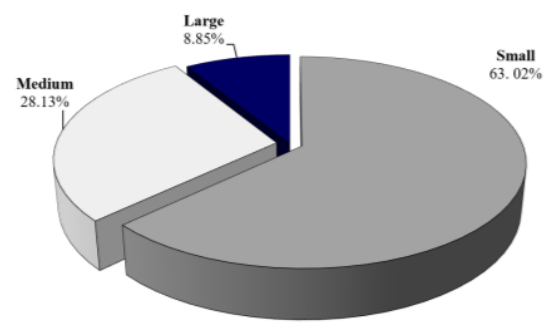

Fig. 1. The percent number of understorey species falling within three different flower size groups.

The distribution of flower size was more or less uniform among the three habit groups (Fig. 2) with no significant relationship between the two variables, the flower size and plant height $\left(\chi^{2}=\right.$ $1.31, \mathrm{df}=4, P=0.85)$. The flower size was quite variable and significantly different among polytypic families (Fig. 3), $\left(\chi^{2}=116.02\right.$, df $=80, P=0.006$ ). Monotypic families showed no such wide variations.

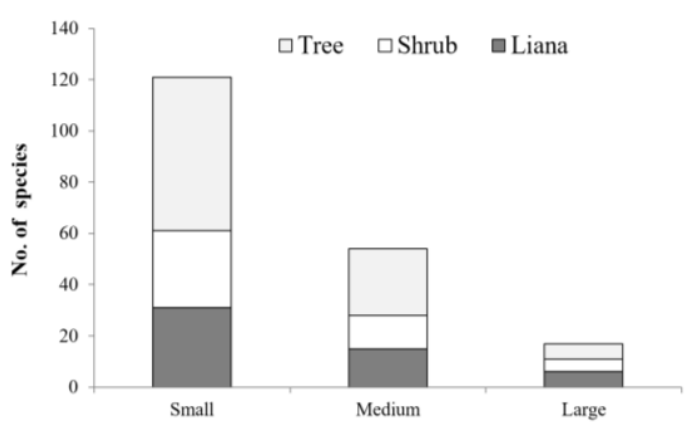

Fig. 2. The number of understory species within three different flower size groups. 
Among the polytypic families, Asteraceae, Leeaceae, Poaceae, Samydaceae, Arecaceae, Celastraceae, Ehretiaceae, Lauraceae, Santalaceae and Ulmaceae mostly possessed small - sized flowers in general. While, 4 families namely, Convolvulaceae, Acanthaceae, Myrtaceae and Santalaceae constituted understorey species with medium - sized flowers. The understorey species of family Caesalpiniaceae showed greater number of large - sized flowers
(Fig. 3). The fruit size (length $\times$ width) was less than $0.1 \mathrm{~cm}^{2}$ in Adenostema viscosum Forst., Colebroakia oppositifolia Sm. Exot., Embelia ribes Burm.f., Callicarpa macrophylla Vahl., Mikania cordata Burm.f., Wendlandia heynei (R. \& S.) Santapau, Wendlandia puberula DC. Prodr. and Eupatorium odoratum Linn. The species such as Haplophragma adenopbyllum Wall. and Oroxylum indicum (Linn.) showed fruits large than $100 \mathrm{~cm}^{2}$.

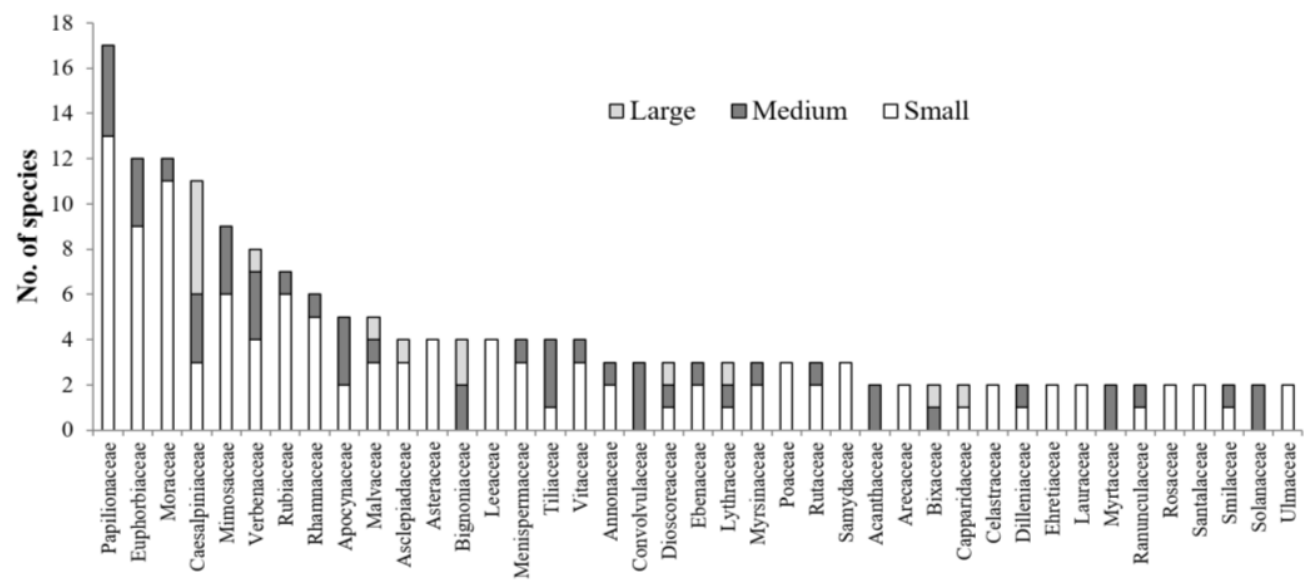

Polytypic families

Fig. 3. The number of understorey species under polytypic families showing different flower size within forested landscape of north-eastern Uttar Pradesh.

Table 1. Relationship between different traits of understory plants of sal forests of north-eastern Uttar Pradesh.

\begin{tabular}{|c|c|c|c|c|c|}
\hline Trait variables $\#$ & $\mathbf{R}^{2}$ & $\mathbf{t}$ & & $P$ & Regression model* \\
\hline \multicolumn{6}{|l|}{ Plant height } \\
\hline Leaf length & 0.025 & & 2.23 & 0.026 & $y=0.479+0.556 x$ \\
\hline Leaf width & 0.045 & & 2.98 & 0.003 & $y=-0.137+0.809 x$ \\
\hline Flower size & 0.007 & & 1.21 & 0.226 & \\
\hline Fruit size & 0.039 & & 2.81 & 0.005 & $y=-9.564+11.43 x$ \\
\hline \multicolumn{6}{|l|}{ Leaf length } \\
\hline Leaf width & 0.591 & & 16.56 & $<0.0001$ & $y=-0.470+1.073 x$ \\
\hline Flower size & 0.001 & & 0.58 & 0.562 & \\
\hline Fruit size & 0.003 & 0.76 & & 0.445 & \\
\hline \multicolumn{6}{|l|}{ Leaf width } \\
\hline Flower size & 0.019 & & 1.93 & 0.054 & \\
\hline Fruit size & 0.0005 & & 0.31 & 0.75 & \\
\hline \multicolumn{6}{|l|}{ Flower size } \\
\hline Fruit size & 0.132 & & 5.39 & $<0.0001$ & $y=-0.293+4.134 x$ \\
\hline
\end{tabular}

\#Trait variable are measured in centimeter $(\mathrm{cm})$, except plant height $(\mathrm{m})$ and flower size $\left(\mathrm{cm}^{2}\right) . *$ The model is based on standardized major axis (SMA/MA) regression and is only shown for significant relation. Significant probability levels are shown in bold. All traits were $\log _{10}$-transformed prior to analysis. $\mathrm{N}=192$.

The relationships among the various morphometric traits are shown in (fig. 4-7) and (Table 1). A significant positive relationship was noticed between plant height and each of the leaf length, leaf width and fruit size. These trait associations were albeit quite weakly related (Fig. 4a, b, d and table 1) but the leaf length and leaf width showed strong and positive correlation $\left(\mathrm{R}^{2}=0.59, P<\right.$ 0.0001, (Fig. 5a, Table 1). Flower size and fruit size also showed strong positive association $\left(\mathrm{R}^{2}=\right.$ $0.13, P<0.0001$, (Fig. 7, Table 1). Thus, only $13 \%$ change in the fruit size was statistically affected by flower size. Correlation between plant height and flower size, leaf length and flower size and with fruit size (Fig. 5 b,c) and that between leaf width and flower size and the fruit size was quite weak (Fig. 6a, b). The mean values of five functional traits of the three habit groups are shown in (Table 2). Of these, plant height (F value $=55.88, P<$ $0.0001)$ and fruit size showed significant variation among the three habit groups ( $\mathrm{F}$ value $=4.44, P=$ 0.01). Further the mean difference of leaf length $(P$ $=0.57)$, leaf width $(P=0.08)$ and flower size $(P=$ $0.78)$ among different habit groups were nonsignificant (Table 2). 

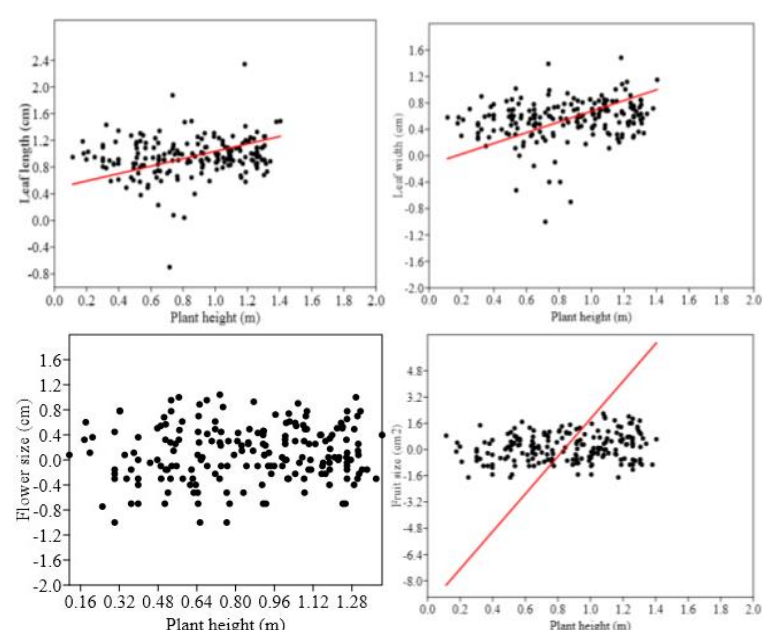

Fig. 4. Relationship between plant height with leaf length (a), leaf width (b), flower size (c) and fruit size (d)

Among 193 woody understorey species within forested landscape of north-eastern Uttar Pradesh. Each data point represents $\log _{10}$-transformed value for a species. Regression statistics are given in Table 1. The straight line indicates significant association. The Standardized major axis (SMA/MA) slopes (and 95\% confidence interval) of significant traits are as follows: (a) leaf length: $0.556(-0.924,1.012)$, (b) leaf width: $0.809(-0.428,1.325)$, (d) fruit size: $11.43(-10.577,16.035)$.

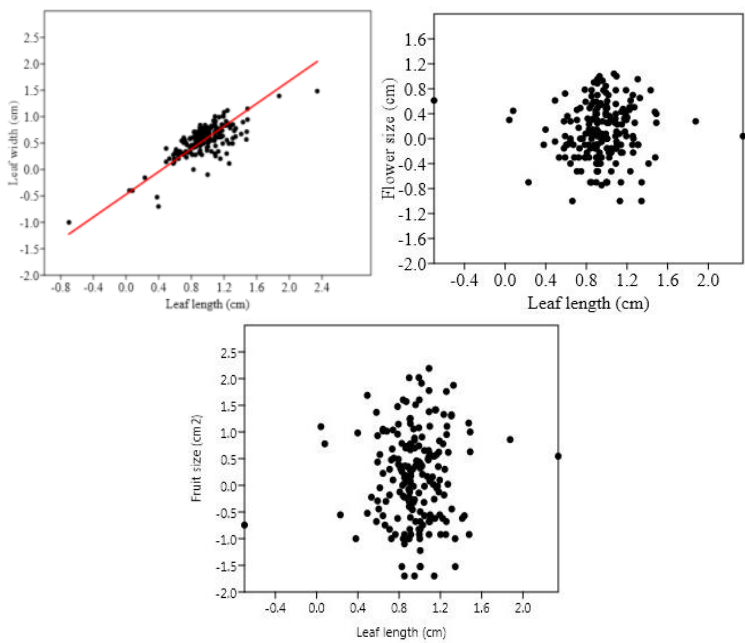

Fig. 5. Relationship between leaf length with leaf width (a), flower size (b) and fruit size (c).

Each data point represents $\log _{10}$-transformed value for a species. Regression statistics are given in Table 1. The straight line indicates significant association. The SMA slopes (and 95\% CI) of significant trait are as follows: (a) leaf width: $1.073(0.832,1.222)$.
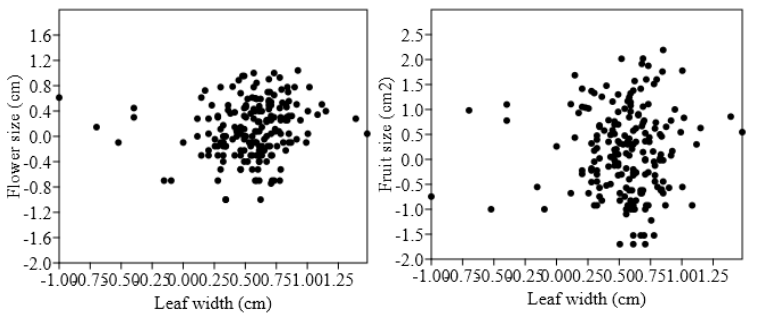

Fig. 6. Relationship between Leaf width with flower size (a) and fruit size (b).

Each data point represents $\log _{10}$-transformed value for a species. Regression statistics are given in Table 1. The lack of straight line indicates non-significant association.

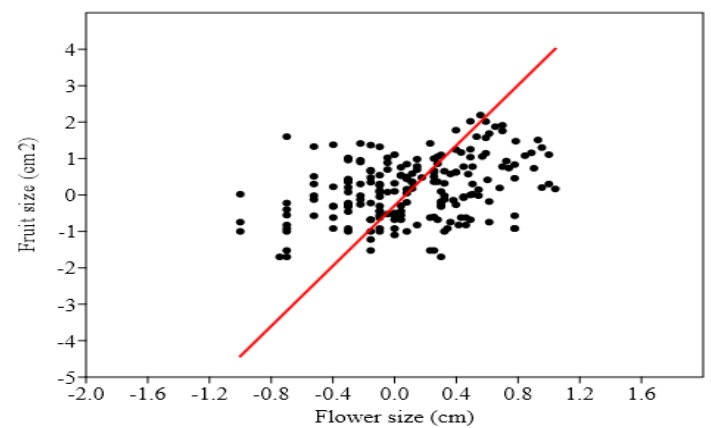

Fig. 7. Relationship between flower size with fruit size.

Each data point represents $\log _{10}$-transformed value for a species. Regression statistics are given in Table 1. The straight line indicates significant association. The SMA slopes (and 95\% CI) are as follows: (a) leaf width: 46.534 (-312.65, 609.38).

Table 2. The Mean \pm S.E. values with their ANOVA test between plant functional traits of sal forest of north-eastern Uttar Pradesh.

\begin{tabular}{lllccc}
\hline $\begin{array}{c}\text { Functional } \\
\text { traits }\end{array}$ & \multicolumn{1}{c}{ Tree } & \multicolumn{1}{c}{ Shrub } & Liana & F & $\boldsymbol{P}$ \\
\hline Plant height & $12.11 \pm 0.57^{\mathbf{b}, \mathbf{c}}$ & $3.18 \pm 0.50^{\mathrm{a}, \mathbf{c}}$ & $9.11 \pm 0.75^{\mathrm{a}, \mathrm{b}}$ & 55.88 & 0.0001 \\
Leaf length & $12.68 \pm 2.35$ & $9.52 \pm 0.76$ & $11.62 \pm 1.48$ & 0.56 & 0.57 \\
Leaf width & $4.48 \pm 0.37$ & $3.57 \pm 0.28$ & $5.02 \pm 0.52$ & 2.50 & 0.08 \\
Flower size & $1.92 \pm 0.19$ & $1.14 \pm 0.35$ & $2.13 \pm 0.31$ & 0.24 & 0.78 \\
Fruit size & $11.98 \pm 2.69^{\mathbf{d}}$ & $2.81 \pm 1.08^{\mathrm{d}}$ & $5.25 \pm 1.19$ & 4.44 & 0.01 \\
\hline $\begin{array}{l}\text { Similar letters in the row indicates significant variation }(P<0.05) \\
\text { among tree, shrub and liana after Bonferroni's multiple }\end{array}$ & & \\
comparision test.
\end{tabular}

\section{Discussion}

The morphological traits and their interrelationship among understorey species have been analyzed to understand the quantitative variation within regional sal dominated forests. Trait-based approaches have been increasingly adopted to disentangle the different processes in community ecology (Kraft et al., 2008, Messier et al., 2016). The patterns of trait variation can be observed at different ecological scales or for different regions (Roche et al., 2004, Hulshof and Swenson 2010, Messier et al., 2010, Auger and Shipley 2013, Kang et al., 2014). 
The understorey vegetation of the regional sal forest was studied to investigate the trait relationship among the species of this stratum. A greater proportion of species exhibited small- sized flowers. It may be due to the fact that flower visitors are showed to the wide array of unspecialized flowers within the community (Bawa et al., 1985). These unspecialized flowers may partly be attributed to the scarcity of larger unspecialized insects. Such cases have been reported from Hawaii, New Zealand and Australia (Lloyd 1985). The observation suggested that the relationship between that plant height and flower size, leaf length and flower size, leaf length and fruit size, leaf width and flower size and leaf width and fruit size are orthogonal and the orthogonality of these morphometric parameters indicate that the dimensions among different parameters convey essentially different information (Ackerly 2004). Despite this, several quite consistent and positive but mostly weak relationships were found between plant height and each of leaf length, width and flower size and fruit size in regional sal forest. However, a strong positive relationship was evident between leaf length and leaf width as also reported elsewhere (Valencia et. al 2016). Leaf size and it's interspecific variation is important in terms of leaf energy and water balance since it is connected with climatic variation.

A tendancy for larger species to have larger fruit was observed in the region and has also been recognized by several workers (Leishman et al., 2000, Moles et al., 2004, Wright et al., 2007). It is unclear why larger species tend to have larger fruits while, logically, there must be a physical constraint whereby small plants could not support large fruits. (Cornelissen 1999 and Wright et al., 2007) reported positive correlation between leaf size and fruit size while, in the present forest such relationship was not noticed. It may be due to the fact that the dimensions of leaves and fruits were limited only to their maximum length and width. Our data concur with Osunkoya (1996) in that, there is significant positive correlations between fruit size and flower sizes. Whitney and Rudgers (2009) also observed similar results for 472 plant species from three flora of USA. Plant height was associated with the competitive vigour, fecundity and regeneration time of the plant species after a disturbance (Cornelissen et al., 2003). Generally, shade - tolerant species invest more in lateral expansion of the crown, thus, increasing light interception under shaded conditions. Whereas light - demanding species invest more in height growth to avoid being shaded neighbours (Shukla and Ramakrishnan 1986). The qualitative analysis and the relationship among ecologically important morphological plant traits traits provides better understanding of morphological trait variation of species of understorey of regional sal dominated forests.

\section{Acknowledgments}

We are thankful to the Head, Department of Botany, DDU Gorakhpur University, Gorakhpur for providing laboratory facilities and forest officers of Gorakhpur Forest Division for their active cooperation in the field. The authors are thankful to Prof. (Dr.) Hatice Nurhan Büyükkartal for their comments and suggestions.

\section{References}

1. Ackerly, D. D. 2004. Adaptation, niche conservatism, and convergence: comparative studies of leaf evolution in the California chaparral. American Nature 163: 654-671.

2. Auger, S. \& B. Shipley. 2013. Inter-specific and intra-specific trait variation along short environmental gradients in an old-growth temperate forest. Journal of Vegetation Science 24: 419-428.

3. Bawa, K.S., S.H. Bullock, D.R., R.E. Coville \& M.H. Grayum. 1985. Reproductive biology of tropical lowland rain forest trees. II. Pollination systems. Americal Journal of Botany 72: 346-356.

4. Campbell, D.R., N.M. Waser \& E.J. MeléndezAckerman. 1997. Analyzing pollinator mediated selection in a plant hybrid zone: hummingbird visitation patterns on three spatial scales. American Nature 149: 295-315.

5. Carpenter, F. L. 1976. Plant-pollinator interactions in Hawaii: Pollination energetics of Metrosideros collina (Myrtaceae). Ecology 57: 1125-1144.

6. Carpenter, T., Franke, M., \& Levi, L. (2003). Thinking mathematically: Integrating arithmetic and algebra in elementary school. Portsmouth: Heinemann.

7. Cornelissen, J.H.C. 1999. A triangular relationship between leaf size and seed size among woody species: allometry, ontogeny, ecology, and taxonomy. Oecologia 118: 248-255.

8. Cornelissen, J.H.C., P. Castro-Díez \& R. Hunt. 1996. Seedling growth, allocation and leaf attributes in a wide range of woody plant species and types. Journal of Ecology 84: 755-765.

9. Cornelissen., J.H.C. S. Lavorel, E. Garnier, S. Diaz, N. Buchmann, D. E. Gurvich, P.B. Reiach, H. ter Steege, H.D. Morgan, M.G.A. van der Heijden, J. G. Pausas \& H. Poorter 2003. A handbook of protocols for standardized and easy measurement of plant functional traits worldwide. American Journal of Botany 51: 335-380.

10. Corner, E.J.H. 1949. Durian theory or the origin of the modern tree. Annals of Botany 13: 367-414.

11. Díaz, S. \& Cabido, M. 2001. Plant functional diversity matters to ecosystem processes. Trends of Ecology and Evolution 16: 646-655.

12. Dolédec, S. \& D. Chessel. 1994. Co-inertia analysis: an alternative method for studying species- 
environment relationships. Freshwater Biology 31: 277-294.

13. Fonseca, C.R., J.M. Overton, B. Collins \& M. Westoby. 2000. Shifts in trait combinations along rainfall and phosphorus gradients. Journal of Ecology 88: 964-977.

14. Givnish, T.J. 1978. Ecological aspects of plant morphology: leaf form in relation to environment. Theoretical Plant Morphology (ed. R. Sattler) 83-142. Leiden University Press, Leiden.

15. Givnish, T. J. 1987. Comparative studies of leaf form: assessing the relative roles of selective pressures and phylogenetic constraints. New Phytologist 106: 131-160.

16. Gregory-Wodzicki, K.M. 2000. Relationships between leaf morphology and climate, Bolivia: implications for estimating paleoclimate from fossil floras. Paleobiology 26: 668-688.

17. Hammer, Øyvind (1999-2012). PAST, PAleontological Statistics, Version 2.17, University of Oslo ohammer@nhm.uio.no

18. Hendry, G.A.F. \& J.P. Grime. 1993. Methods in comparative plant ecology-a manual of laboratory methods. London: Chapman and Hall.

19. Hulshof, C.M. \& N.G. Swenson. 2010. Variation in leaf functional trait values within and across individuals and species: an example from a Costa Rican dry forest. Functional Ecology 24: 217-223.

20. Kang, M., S.X. Chang, E.R. Yan \& X.H. Wang. 2014. Trait variability differs between leaf and wood tissues across ecological scales in subtropical forests. Journal of Vegetation Science 25: 703-714.

21. Kraft, N.J., R. Valencia \& D.D. Ackerly 2008. Functional traits and niche-based tree community assembly in an Amazonian forest. Science 322: 580582.

22. Lavorel, S., S. McIntyre, J. Landsberg \& T.D.A. Forbes. 1997. Plant functional classifications: from general groups to specific groups based on response to disturbance. Trends in Ecology and Evolution 12: 474-478.

23. Leishman, M.R., I.J. Wright, A.T. Moles \& M. Westoby. 2000. The evolutionary ecology of seed size. In: Fenner M, editor. Seeds: the ecology of regeneration in plant communities. Wallingford, UK. CAB International 31-57.

24. Lloyd, D. G. 1985. Progress in understanding the natural history of New Zealand plants. New Zealand. Journal of Botany 23: 707-722.

25. Lord, J., M. Westoby \& M. Leishman. 1995. Seed size and phylogeny in six temperate floras: constraints, niche conservatism, and adaptation. American Nature 146: 349-364.
26. Messier, J., B.J. McGill, B.J. Enquist \& M.J. Lechowicz. 2016. Trait variation and integration across scales: is the leaf economic spectrum present at local scales? Ecography

27. Messier, J., B.J. McGill, B.J. Enquist \& M.J. Lechowicz. 2010. How do traits vary across ecological scales? A case for trait-based ecology. Ecological Letter 13: 838-848.

28. Moles, A.T., D.S. Falster, M.R. Leishman \& M. Westoby. 2004. Small-seeded species produce more seeds per square metre of canopy per year, but not per individual per lifetime. Journal of Ecology 92: 384 396.

29. Murali K.S. 1997. Patterns of seed size, germination and seed viability of tropical tree species in southern India. Biotropica 29: 271-279.

30. Osunkoya, O. O. 1996. Light requirements for regeneration in tropical forest plants: taxon-level and ecological attribute effects. Australian Journal of Ecology 21: 429-441.

31. Pandey, S.K. \& R.P. Shukla. 2003. Plant diversity in managed sal (Shorea robusta Gaertn) forests of Gorakhpur, India: species composition, regeneration and conservation. Biodiversity and Conservation 12: 2295-2319.

32. Roche, P., N. Díaz-Burlinson \& S. Gachet. 2004 Congruency analysis of species ranking based on leaf traits: which traits are the more reliable? Plant Ecology 174: 37-48.

33. Sagar, R. \& J.S. Singh. 2003. Predominant phenotypic traits of disturbed tropical dry deciduous forest vegetation in northern India. Community Ecology 4 : 63-71.

34. Srivastava, T.N. 1976. Flora Gorakhpurensis. Today \& Tomorrow's Printers \& Publishers, New Delhi, India.

35. Srivastava, S., A. Dvivedi \& R.P. Shukla. 2015. Commonness and rarity pattern of plant species within Terai grassland of north- eastern Uttar Pradesh, India. Tropical Grasslands 3: 161-186.

36. Shukla, R.P. \& P.S Ramakrishnan. 1986. Architecture and growth strategies of tropical trees in relation to successional status, Journal of Ecology. 74: $33-46$

37. Shukla, R.P. 2009. Pattern of plant species diversity across Terai landscape in north-eastern Uttar Pradesh, India. Tropical Ecology 50: 111-123.

38. Vivek, P. \& N. Parthasarathy. 2015. Liana community and functional trait analysis in tropical dry evergreen forest of India. Journal of Plant Ecology 8: 501-512.

39. Valencia, E., E. Valencia, L. José Quero \& T. Fernando. 2016. Maestre Journal of Plant Ecology 9: 773-783. 
40. Walker, B., A. Kinzig \& J. Langridge. 1999. Plant attribute diversity, resilience, and ecosystem function: the nature and significance of dominant and minor species. Ecosystems 2: 95-113.

41. Westoby, M. \& I.J. Wright. 2003. The leaf size-twig size spectrum and its relationship to other important spectra of variation among species. Oecologia 135: 621-628.

42. Westoby, M. 1998. A leaf-height-seed (LHS) plant ecology strategy scheme. Plant Soil 199:213-227.

43. Westoby, M., D.S. Falster, A.T. Moles, P.A. Vesk \& I. J. Wright. 2002. Plant ecological strategies: some leading dimensions of variation between species. Annual Review of Ecology and Systematics 33:125-159.

44. Whitney, K.D. \& J.A. Rudgers. 2009. Constraints on plant signals and rewards to multiple mutualists? Plant Signal Behaviour 4:1-4.
45. Wright, I.J. 2007. Relationships among key dimensions of plant trait variation in seven Neotropical forests. Annals of Botany 99: 1003-1015.

46. Wright, I.J., P.B. Reich, J.H.C. Cornelissen, D.S Falster, E. Garnier, K. Hikosaka, B.B. Lamont, W. Lee, J. Oleksyn, N. Osada, H. Poorter, R. Villar, D.I. Warton \& M. Westoby. 2005. Assessing the generality of global leaf trait relationships. New Phytologist 166: 485-496.

\section{Cite this article as:}

Satish Kumar Rai, Ravindra P. Shukla and Sanjay Kumar Pandey. The morphological traits variation and interrelationships of understorey species of sal (Shorea robusta) forest of north-eastern Uttar Pradesh, India. Annals of Plant Sciences 7.4 (2018) pp. 2178-2184.

do $\mathrm{http://dx.doi.org/10.21746/aps.2018.7.4.18}$

Source of support: Department of Botany, DDU Gorakhpur University Conflict of interest: Nil 